\title{
Cavernous lymphangioma of the urinary bladder in an adult woman: an additional case report of a rare lesion and literature review
}

\author{
Wei He ${ }^{1}$, Li Jin², Fang-fang Lin³ ${ }^{3}$ Xiao-long Qi ${ }^{1}$, Xiang-lei He², Da-hong Zhang ${ }^{1}$ and Ming Zhao ${ }^{2^{*}}$ (D)
}

\begin{abstract}
Background: Urinary bladder lymphangioma is a rare and benign lesion that is often causes symptoms related to irritation and urinary tract obstruction. Because a lymphangioma may resemble a true neoplasm of the urinary bladder clinically, the lesion must be removed for accurate histologic diagnosis and to rule out malignancy.

Case presentation: We present a case of a 40-year-old female who was evaluated for painless gross hematuria. Clinical and diagnostic work up revealed a sharply defined mass involving the wall and bulging into the cavity on the dome of the bladder. Partial cystectomy was performed and histologic findings were compatible with cavernous lymphangioma. The symptom of hematuria relieved after the procedure and the patient was in good status without evidence of recurrence by cystoscopy at follow-up 6 months later.
\end{abstract}

Conclusions: Lymphangioma of the urinary bladder is treated with surgical excision and seems to have no recurrence once completely resected, but long-time follow-up may be needed.

Keywords: Lymphangioma, Bladder tumor, Mesenchymal tumor, Case report

\section{Background}

Lymphangioma is rare benign vascular lesion composed of a localized collection of dilated lymphatic channels, which has been classified into three histologic groups depending on the size of lymphatic spaces as capillary, cavernous, and cystic [1]. Lymphangioma usually affects children and infrequently occurs in adults, and is typically formed in the neck and axillary regions [2]. Lymphangioma is very rarely seen in the urinary bladder and to our knowledge only five such cases have been reported worldwide since 1983 [3-7]. This article describes an additional case of lymphangioma involving the urinary bladder in an adult Chinese woman and the clinical

\footnotetext{
*Correspondence: zhaomingpathol@163.com

2 Department of Pathology, Laboratory Medicine Center, Zhejiang

Provincial People's Hospital, People's Hospital of Hangzhou Medical

College, Hangzhou 310014, Zhejiang, China

Full list of author information is available at the end of the article
}

presentations, imaging characteristics as well as the gross and histologic features of the lesion are summarized.

\section{Case presentation}

A 40-year-old woman presented with painless gross terminal hematuria for 6 months. Urinalysis showed red blood cells notable for 65 per high power field and a negative urine culture. Computerized tomography (CT) scan showed a sharply defined, heterogeneously enhancing mass involving the dome of the urinary bladder wall measuring $4.0 \mathrm{~cm}$ in the maximum diameter (Fig. 1a). Cystoscopy examination revealed a red, non-papillary tumor with a smooth surface, bulging into the cavity on the dome of the bladder (Fig. 1b). Transurethral resection biopsy of the mass was carried out and histopathology revealed chronic inflammation with focally florid von Brunn's nests that cannot excluded a nested variant of urothelial carcinoma. A subsequent laparoscopically partial cystectomy (including the mass and a small amount 

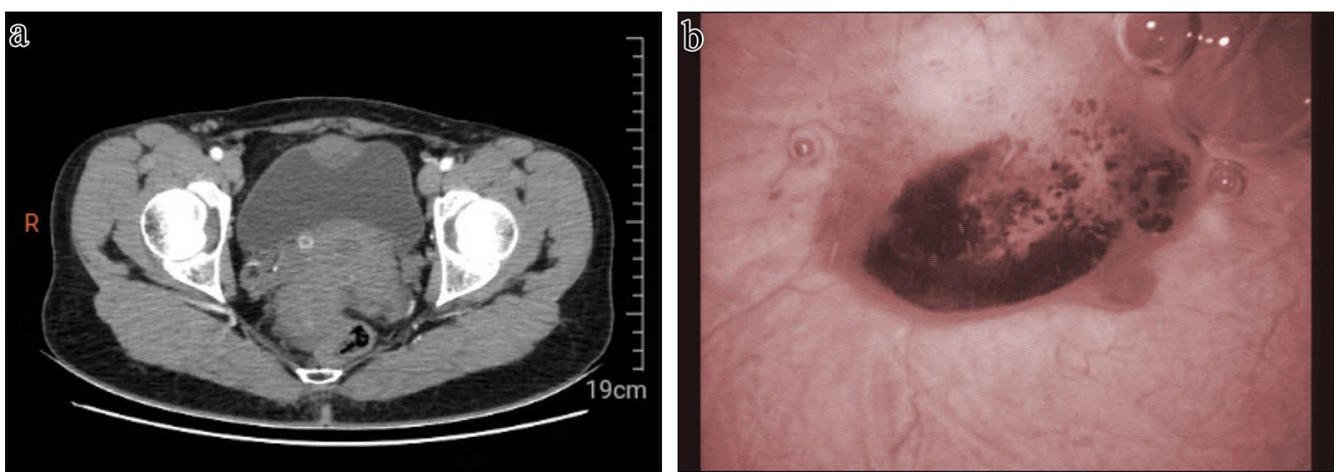

Fig. 1 a Computerized tomography scan showed a sharply defined mass involving the dome of the urinary bladder wall. b Cystoscopy examination revealed a non-papillary tumor with a smooth surface with hemorrhage, bulging into the cavity on the dome of the bladder

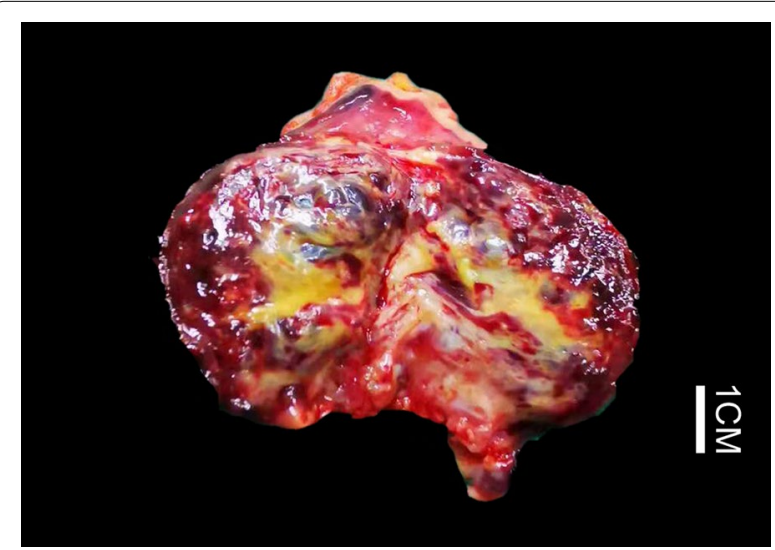

Fig. 2 Gross examination demonstrated a predominantly solid tumor with numerous tiny dilated cysts containing chylous to yellow cheese-like fluid of adjacent bladder tissues) was performed and the specimen was sent for intraoperative frozen section consultation, which indicated a benign mesenchymal lesion in favor of a hemangioma. The tumor was completely removed with negative resection margins. The symptom of hematuria relieved after the procedure and the patient was in good status without evidence of recurrence by cystoscopy at follow-up 6 months later.

The cut surface of the resection specimen demonstrated a predominantly solid tumor of $3.8 \mathrm{~cm}$ in the maximum diameter and gray red in color with numerous tiny dilated cysts containing chylous to yellow cheeselike fluid (Fig. 2). The covered mucosa was unremarkable grossly. Microscopically, the tumor was consisted of variably sized dilated lymphatic vessels lined by flattened endothelium which involved the full-thickness of

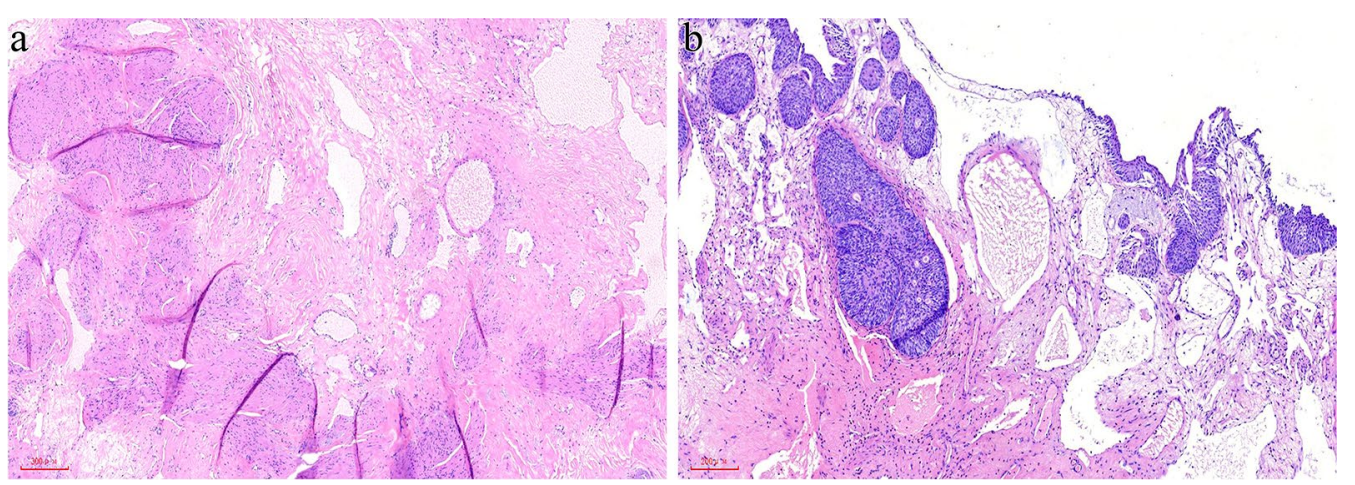

Fig. 3 a Pathological findings revealed that the tumor was consisted of variably sized dilated lymphatic vessels which involved the full-thickness of the bladder wall and often dissected the muscularis propria. $\mathbf{b}$ In superficial mucosa there were clustering of thin-walled dilated lymphatics accompanied with focally florid von Brunn's nests hyperplasia of the overlying urothelium 
the bladder wall and often dissected the muscularis propria (Fig. 3a). In superficial mucosa the dilated lymphatics were thin-walled that connected with thick-walled often muscular, lymphatic channels in the deep muscularis propria, and the overlying urothelium showed flatten hyperplasia with focally florid von Brunn's nests formation (Fig. 3b). By immunohistochemistry (IHC), the endothelium lining of the vascular channels showed positive stains for D2-40 and CD31, further confirming their lymphatic properties. Based the histologic and IHC features, the diagnosis of cavernous lymphangioma was rendered.

\section{Discussion and conclusions}

Regarded as an abnormality of morphogenesis rather than as a neoplasm, lymphangioma is now also referred to as lymphatic malformation [2]. It affects almost any part of the body served by the lymphatic system but shows a predilection for the head, neck, and axilla and only sporadically occurs in internal organs or intraabdominal locations where it can produce site-specific signs and symptoms [2].

Mesenchymal tumors of the urinary bladder are rare, and lymphangiomas among them are even rarer. Of the previously reported 5 patients with lymphangioma involving the urinary bladder (Table 1), 3 were adults and 2 were children, most of whom were manifested as painless gross hematuria, a symptom that is associated with hemorrhage of the lymphangioma or infection [5]. The first case reported by Bolkier et al. [3] in 1983 was a child with a $10 \times 5 \times 2 \mathrm{~cm}$ lesion starting from the wall of the bladder and invading the peritoneal cavity through the bladder wall. The second case reported by Wyle et al. [4] was a 49-year-old man presented with irritative voiding symptoms; cystoscopy showed a non-papillary tumor between the 2 orifices within the trigone. The third case reported by Niu et al. [5] was an 8-year-old girl whose tumor appeared as a shiny red mass in cystoscopy, and a bulge into the bladder on the right lateral wall was detected by imaging studies. The fourth case reported by Seyam et al. [6] was a 27-year-old woman; CT scan showed a heterogeneously enhancing mass arising from the anterior urinary bladder wall measuring $3.8 \times 3.6 \mathrm{~cm}$ and cystoscopy showed a solid mass at the dome of the bladder covered by a normal mucosa. The fifth case reported by Moradi et al. [7] was a 40-year-old woman with a flat, $4 \mathrm{~mm}$ strawberry-like lesion on the right lateral wall of the bladder noticed by urethrocystoscopy.

Since its rarity, lymphangioma in the urinary bladder is extremely difficult to properly diagnose preoperatively, and histological examination is essential for the correct diagnosis. In most cases, the histologic diagnosis of lymphangioma is straightful, although some with secondary hemorrhage can resemble a cavernous hemangioma, and those with a significant amount of smooth muscle within the wall of the lymphatic vessels resemble

Table 1 Clinical data from previous cases and the current case of lymphangioma of the urinary bladder

\begin{tabular}{|c|c|c|c|c|c|c|c|c|}
\hline $\begin{array}{l}\text { Case no./ } \\
\text { references }\end{array}$ & Age (years) & Sex & $\begin{array}{l}\text { Clinical } \\
\text { presentations }\end{array}$ & $\begin{array}{l}\text { Cystoscopy } \\
\text { features }\end{array}$ & Size $(\mathrm{mm})$ & Location & $\begin{array}{l}\text { Surgical } \\
\text { approaches }\end{array}$ & $\begin{array}{l}\text { Follow-up } \\
\text { (months) }\end{array}$ \\
\hline $1 /[3]$ & Child & NA & $\begin{array}{l}\text { Painless macro- } \\
\text { scopic hematuria }\end{array}$ & NA & 100 & $\begin{array}{l}\text { Lateral wall, } \\
\text { unknown side }\end{array}$ & Partial cystectomy & NA \\
\hline $2 /[4]$ & 49 & M & $\begin{array}{l}\text { Irritative voiding } \\
\text { symptoms }\end{array}$ & $\begin{array}{l}\text { A non-papillary } \\
\text { tumor with a } \\
\text { smooth surface }\end{array}$ & NA & $\begin{array}{l}\text { Between the two } \\
\text { orifices within the } \\
\text { trigone }\end{array}$ & $\begin{array}{l}\text { Transurethral } \\
\text { resection }\end{array}$ & $\begin{array}{l}\text { Symptoms } \\
\text { improved, } 3\end{array}$ \\
\hline $3 /[5]$ & 8 & $\mathrm{~F}$ & $\begin{array}{l}\text { Terminal hematu- } \\
\text { ria associated with } \\
\text { intermitted fever } \\
\text { over } 1 \text { week }\end{array}$ & $\begin{array}{l}\text { A small red tumor } \\
\text { bulging into the } \\
\text { bladder cavity }\end{array}$ & 5 & Right lateral wall & Partial cystectomy & NED, 36 \\
\hline $4 /[6]$ & 27 & $\mathrm{~F}$ & $\begin{array}{l}\text { Painless gross } \\
\text { hematuria for } \\
6 \text { months with } \\
\text { occasional } \\
\text { suprapubic pain }\end{array}$ & $\begin{array}{l}\text { A mobile and solid } \\
\text { mass covered by a } \\
\text { normal mucosa }\end{array}$ & 38 & Dome & $\begin{array}{l}\text { Robotic partial } \\
\text { cystectomy }\end{array}$ & NED, 6 \\
\hline $5 /[7]$ & 40 & $\mathrm{~F}$ & $\begin{array}{l}\text { Alternative micro- } \\
\text { scopic hematuria } \\
\text { for } 3 \text { months }\end{array}$ & $\begin{array}{l}\text { A flat highlighted } \\
\text { strawberry-like } \\
\text { lesion }\end{array}$ & 4 & Right lateral wall & $\begin{array}{l}\text { Holmium laser } \\
\text { ablation }\end{array}$ & NED, 24 \\
\hline 6/current case & 40 & $\mathrm{~F}$ & $\begin{array}{l}\text { Painless gross } \\
\text { hematuria for } \\
6 \text { months }\end{array}$ & $\begin{array}{l}\text { A red, non-papil- } \\
\text { lary tumor with a } \\
\text { smooth surface, } \\
\text { bulging into the } \\
\text { cavity }\end{array}$ & 38 & Dome & Partial cystectomy & NED, 6 \\
\hline
\end{tabular}


a venous malformation. Histologic features that favor the diagnosis of lymphangioma over a hemangioma are lymphoid aggregates in the stroma and more irregular lumens with widely spaced nuclei [2]. IHC for lymphatic differentiation markers, such as D2-40, prospero homeobox 1(PROX1) and vascular endothelial growth factor receptor 3 (VEGFR3), is ultimately the most reliable means for distinguishing the two entities [8]. Similar to its cutaneous counterparts that often demonstrate hyperplasia of the epidermis [1], lymphangioma of the urinary bladder can also cause overlying urothelial hyperplasia and sometimes with florid von Brunn's nests hyperplasia, which in cystoscopy biopsy may obscure the underlying lymphangioma and cause diagnostic confusions with urothelial carcinoma, especially for nested variant urothelial carcinoma.

Lymphangioma is typically benign, but because of its propensity for involvement of deeper tissue planes, recurrences have been documented in as many as $20 \%$ of patients after removal of superficial lesions [1]. Including our case, the 6 patients of bladder lymphangioma reported in the literature so far have not experienced tumor recurrence after surgery, but the follow-up time is limited (from 3 months to 3 years). Treatments consist of partial cystectomy for 4 patients, and transurethral resection and holmium laser ablation for one each patient [3-7]. Because urinary bladder lymphangioma is usually larger than it appears and often dissecting the full-thickness of the wall, complete resection is warranted to prevent recurrence. For this reason, partial cystectomy is the preferable treatment procedure than transurethral resection or laser ablation, particularly for lesions with larger size by cystoscopy or imaging evaluations.

In conclusion, lymphangioma arising in the urinary bladder is extremely rare, and only five cases have been identifed in studies reported in English. It is difficult to diagnose bladder lymphangioma according to its clinical features. The gold standard method used for its diagnosis is histopathology.

Lymphangioma of the urinary bladder is treated with surgical excision and seems to have no recurrence once completely resected, but long-time follow-up may be needed.

\section{Abbreviations}

CT: Computerized tomography; IHC: Immunohistochemistry; PROX1: Prospero homeobox 1; VEGFR3: Vascular endothelial growth factor receptor 3.

\section{Acknowledgements \\ None.}

\section{Authors' contributions}

WH wrote the manuscript. $L J$ and $M Z$ diagnosed the case by histopathology and immunohistochemistry. $\mathrm{FL}, \mathrm{XQ}, \mathrm{XH}$ and $\mathrm{DZ}$ analyzed the data and revised the manuscript, and $\mathrm{MZ}$ revised and edited the manuscript. All authors read and approved the final manuscript.

\section{Funding}

This study was supported by Zhejiang Provincial Natural Science Foundation (LY21H160052), Zhejiang Provincial Medicine and Health Research Foundation (2018KY246, 2019KY020). Both funding bodies were involved in the design of the study.

\section{Availability of data and materials}

Records and data pertaining to this case are in the patient's secure medical records in Zhejiang Provincial People's Hospital, People's Hospital of Hangzhou Medical College. All searched data by literature review are included in this paper.

\section{Declarations}

Ethics approval and consent to participate

Not applicable.

\section{Consent for publication}

Written informed consent was obtained from the patient for publication of this case report and any accompanying images. A copy of the consent form is available for review by the Editor of this journal.

\section{Competing interests}

The authors declare that they have no competing interests.

\section{Author details}

'Department of Urology, Zhejiang Provincial People's Hospital, People's Hospital of Hangzhou Medical College, Hangzhou 310014, Zhejiang, China. ${ }^{2}$ Department of Pathology, Laboratory Medicine Center, Zhejiang Provincial People's Hospital, People's Hospital of Hangzhou Medical College, Hangzhou 310014 Zhejiang, China. ${ }^{3}$ Department of Pathology, Jiangshan People's Hospital, Quzhou 324100, Zhejiang, China.

Received: 30 April 2021 Accepted: 1 October 2021

Published online: 13 October 2021

\section{References}

1. Thway K, Doyle LA. Lymphangioma and lymphangiomatosis. In: WHO Classification of Tumours Editorial Board. Soft tissue and bone tumours. Lyon: International Agency for Research on Cancer; 2020. p. 154-5.

2. Goldblum JR, Folpe AL, Weiss SW. Enzinger \& Weiss's soft tissue tumors. 7th ed. Philadelphia: Elsevier; 2020.

3. Bolkier M, Ginesin Y, Lichtig C, Levin DR. Lymphangioma of bladder. J Urol. 1983;129(5):1049-50.

4. Wyler SF, Bachmann A, Singer G, Gasser TC, Sulser T. First case of lymphangioma of the bladder in an adult. Urol Int. 2004;73(4):374-5.

5. Niu ZB, Yang Y, Hou Y, Chen H, Liu X, Wang CL. Lymphangioma of bladder. Urology. 2010;76(4):955-7.

6. Seyam R, Alzahrani HM, Alkhudair WK, Dababo MA, Al-Otaibi MF. Robotic partial cystectomy for lymphangioma of the urinary bladder in an adult woman. Can Urol Assoc J. 2012;6(1):E8-10.

7. Moradi A, Kazemzadeh Azad B, Fasihi M, Aliakbari F. Bladder lymphangioma treated by holmium laser: extremely rare case report. J Lasers Med Sci. 2020;11(2):226-7.

8. Castro EC, Galambos C. Prox-1 and VEGFR3 antibodies are superior to D2-40 in identifying endothelial cells of lymphatic malformations-a proposal of a new immunohistochemical panel to differentiate lymphatic from other vascular malformations. Pediatr Dev Pathol. 2009;12(3):187-94.

\section{Publisher's Note}

Springer Nature remains neutral with regard to jurisdictional claims in published maps and institutional affiliations. 